\title{
-
}

Criar Educação, Criciúma, v. 10, nº1, jan/jul 2021.- PPGE - UNESC - ISSN 2317-2452

\section{EDUCAÇÃO DE JOVENS E ADULTOS: CONTRIBUIÇÕES FREIREANAS PARA A FORMAÇÃO CIDADÃ}

\author{
Atenuza Pires Cassol ${ }^{1}$ \\ Jodielson da Silva Pereira ${ }^{2}$ \\ Antonio Amorim ${ }^{3}$
}

\section{RESUMO}

Analisamos neste estudo, a Educação de Jovens e Adultos e as contribuições de Paulo Freire ao processo de conhecimento para formação cidadã dos alunos trabalhadores. Queremos saber: qual a contribuição da concepção freireana para a formação e a emancipação de jovens e adultos? Tem como objetivo refletir sobre as contribuições da concepção freireana para a escolarização do sujeito-estudante da EJA. Utilizamos a abordagem qualitativa e a pesquisa bibliográfica para consolidar a investigação. Obtivemos como resultados: que há um reconhecimento nas relações que se estabelecem das práticas educativas para a emancipação dos sujeitos como condição humana; que há uma sistemática negação dos direitos garantidos constitucionalmente; ficou destacada a importância da construção dos saberes vivenciados pelos sujeitos da EJA.

Palavras-chave: Educação de Jovens e Adultos. Formação. Cidadania.

\footnotetext{
${ }_{1}^{1}$ Professora da Rede Municipal de Educação em Barreiras-BA. Mestranda do Mestrado Profissional da Educação de Jovens e Adultos (MPEJA) / Universidade do Estado da Bahia. Email: atenuza@hotmail.com

2 Professor de Tecnologia Educacional. Mestrando do Mestrado Profissional em Gestão e Tecnologias Aplicadas (GESTEC), Universidade do Estado da Bahia. Email: jodielson.silva@hotmail.com

3 Pós- Doutor em Difusão do Conhecimento pela Universidade Federal da Bahia. Professor Titular Pleno da Universidade do Estado da Bahia, Campus I. Gestão, organização, tecnologia e políticas públicas na educação básica da Bahia. Email: antonioamorim52@gmail.com
} 


\title{
ADULT AND YOUTH EDUCATION: FREIREANAS CONTRIBUTIONS TO THE FORMATION A CITIZEN
}

\begin{abstract}
Young and Adults Teaching that the process comes for graduation citizen of workers students in the historical-social context. Our questions are: What the Freirean conception to achieve the formation/ emancipation of young and adult people? This conception to the schooling of the subject-student was evidenced that there is a knowledge in the relations that establishes of the educational practices for the subject emancipations like human condition, denial systematic of constitutionally guaranteed rights; the importance of the construction of the knowledge that was unveiled from the reflection on the reading of each reality and diversity.
\end{abstract}

Key Words: Education of Yung and Adults. Formation. Citizenship.

\section{INTRODUÇÃO}

A história da Educação de Jovens e Adultos ultrapassa décadas de lutas por garantia de oferta de ensino, de aumento de vagas nos diferentes estágios, por recursos públicos por atendimento às necessidades da população jovem, adulta e idosa pela construção de identidade dos sujeitos e a sua permanência nos espaços educativos. Amparada na Legislação Federal através da Constituição de 1988 e da Lei de Diretrizes e Bases - LDB (Lei 9.394/96), que reconheceu a EJA como sendo uma modalidade de educação básica, para atuar na reparação daqueles sujeitos que foram distanciados das salas de aula, que por motivos diversos não concluíram seus estudos.

Diante dessa realidade, nosso maior interesse foi o de refletir sobre os principais fatores que dificultam a melhoria do acesso e da qualidade de ensino da EJA, observando as contribuições de Paulo Freire sobre o papel da escola, do professor, do poder público, do educando e como perspectiva de mudança do cenário apresentado e que necessita reformular ações que fortaleça e dê subsídios na formação dos sujeitos tornando-os resistentes e imbuídos de saberes necessários ao enfrentamento diário de embates por ocupação de espaço por direito. 
Assim, desde as primeiras iniciativas para o reconhecimento da educação de jovens e adultos no espaço escolar, político e social, houve embates. Os movimentos sociais e populares buscavam a garantia do direito à educação pelos trabalhadores junto aos governos através das políticas públicas e programas. Diante dessa situação, a escola é espaço social de empoderamento do sujeito que através do currículo, propostas pedagógicas e práticas educacionais possibilita uma reflexão crítica e contínua da realidade de modo que os alunos trabalhadores compreenda o significado da sua não neutralidade, compromisso e inserção como agente crítico e participante do processo histórico social para a mudança no modo de pensar do homem e no seu reconhecimento como na história.

Desse modo, nossa inquietação é fruto das vivências de sala de aula como professores quando nos diálogos coletivos nos deparamos com discussões antes distanciadas sobre a realidade da educação destinada aos sujeitos da EJA. Diante desta premissa, temos como questão problematizadora: qual contribuição da concepção freireana para a formação e emancipação de jovens e adultos?

O objetivo do estudo foi analisar o processo de emancipação dos jovens e adultos e as contribuições da concepção freireana para a escolarização do sujeitoestudante da EJA; refletir sobre as dificuldades e conquistas da educação de jovens e adultos a partir das ideias de Paulo Freire, compreendendo o processo de reconhecimento da população de trabalhadores da EJA nos espaços escolares.

Destacamos a importância das contribuições de Paulo Freire ao processo de formação dos sujeitos da EJA, observando a ausência dos conhecimentos culturais e sociais destes no processo formativo, como sendo um dos principais fatores de enfraquecimento da condição individual e coletiva dos mesmos, para que possam ser os protagonistas do exercício pleno da cidadania. É preciso que os sujeitos da EJA incorporem os conhecimentos necessários, que sejam capazes de intervir nas decisões e nas concretizações de ações, de políticas públicas e de práticas sociais para a garantia dos direitos dos jovens e adultos trabalhadores, na escola. 


\title{
PROCEDIMENTOS METODOLÓGICOS EMPREENDIDOS
}

Para a realização deste estudo adotamos a pesquisa qualitativa como abordagem de investigação, levando em consideração uma das suas características que é a subjetividade intrínseca na visão de mundo, que harmoniza e reconhece as particularidades e a singularidade nas situações apresentadas através de cada sujeito, dentro da sua cultura, nas experiências de vida.

Observemos a defesa que Minayo (2002, p.21-22) faz da investigação qualitativa:

\begin{abstract}
A pesquisa qualitativa responde a questões muito particulares. Ela se preocupa nas ciências sociais, com um nível de realidade que não pode ser quantificado, ou seja, ela trabalha com um universo de significados, motivos, aspirações, crenças, valores e atitudes, o que corresponde a um espaço muito profundo das relações dos processos e dos fenômenos que não podem ser reduzidos à operacionalização de variáveis.
\end{abstract}

Desse modo, a autora evidencia a interpretação da realidade como sendo um dos aspectos relevantes da pesquisa qualitativa, além da flexibilidade que deve fazer parte de toda a condução do processo. Adotamos como dispositivo estratégico, a pesquisa bibliográfica, por incorporar, segundo Fachin (2010), o ato de ler, de selecionar, de fichar, de organizar, de compreender e de apresentar resultados. Neste sentido, tivemos como principal fonte de consulta os artigos divulgados pelas principais as revistas e os livros que destacam as contribuições de Paulo Freire e de outros autores, para analisar a realidade da EJA, sendo articulada ao contexto social.

Buscamos ainda fundamentar o nosso estudo, em trabalhos efetivados sobre EJA e seu o processo histórico. O nosso processo de leitura foi concretizado a partir de elementos levantados, o que implica na valorização de cada passo dado e das estratégias utilizadas, para a qualidade da investigação. Neste sentido, a sistematização das informações, a fonte geradora de dados para Laville (1999, p. 333), é uma "[...] estratégia de pesquisa com dados existentes através da qual o 
pesquisador se concentra sobre um caso, geralmente escolhido por seu caráter considerado típico, a fim de investigá-lo com profundidade".

Assim, na compreensão do autor, a escolha por um determinado modo de investigação depende de suas características e dos elementos que fornecerão dados importantes ao processo da pesquisa. Sabemos, contudo, que estamos longe de esgotar todas as informações presentes nas fontes utilizadas, mas, foram consideradas aquelas que mais se relacionavam com a produção do conhecimento sobre a concepção freireana de educação, o processo de formação, a valorização e o reconhecimento dos sujeitos da EJA.

\section{PAULO FREIRE NO CONTEXTO EDUCACIONAL BRASILEIRO}

Ao iniciar este estudo, é importante traçar as considerações sobre a vida e carreira do educador pernambucano, Paulo Freire que, com sua prática, oportunizou uma nova perspectiva para a educação de jovens e adultos e, favoreceu o avanço da educação popular. Por isso, ao discutir a história da EJA precisamos destacar a importância de Paulo Freire como exímio educador que esteve à frente em muitos momentos da educação no Brasil.

Paulo Reglus Neves Freire, filho de Temístocles Freire e Edeltrudes Neves Freire, foi um pernambucano que marcou a história educacional de adultos no século XX. Paulo Freire, assim conhecido popularmente, nasceu em 19 de setembro de 1921 no Recife, vindo de família da classe média, berço onde bebeu suas principais fontes para as primeiras vivências de mundo. No decorrer da história brasileira, além do seu feito na educação, a filosofia de Freire causou um grande impacto no cenário políticosocial. Por essa razão, sua história de vida social e educacional, é objeto de pesquisa até os dias atuais. 
Na perspectiva educacional, podemos refletir as palavras de Gadotti (1996, p. 28), quando diz que Freire, foi "[...] orientado pela mãe, escrevendo palavras com gravetos das mangueiras à sombra delas, no chão do quintal da casa onde nasceu, na Estrada do Encanamento, no bairro da Casa Amarela, como tanto gostava de lembrar e dizer". Neste sentido, no Nordeste, Freire constituiu suas primeiras experiências com a educação, tendo como orientadora, a sua mãe. A visão crítica de mundo, o confronto com o contexto vivencial, demarcou a trajetória do educador Paulo Freire, assim como oportunizou carreiras transformadoras na vida de muitos jovens e adultos no âmbito da natureza educativa.

Durante a caminhada desse pedagogo, é importante frisar que, Paulo Freire era cristão, pautado numa teologia solidária e libertadora. Inspirado nas concepções fenomenológicas, do existencialismo e do neomarxismo, o educador propugnou suas primeiras práticas de valorização da pessoa humana e de sua história. Diante dessa premissa, Aranha afirma que:

Antes de tudo, Paulo Freire é cristão. Seu cristianismo, porém, se embasa em uma teologia libertadora, preocupada com o contraste, com a pobreza e a riqueza que resulta dos privilégios sociais. Percorre em seguida os caminhos da fenomenologia, do existencialismo e o neomarxismo (1996, p. 206).

Isso nos faz pensar que a base influenciadora de Freire, a princípio, é direcionada para o indivíduo provido de suas condições perante a sociedade em que vive, uma concepção idealizada pelos princípios do cristianismo, onde dispõe o modo da existência humana. "Existir é um conceito dinâmico. Implica uma dialogação eterna do homem com o homem. Do homem com o seu Criador". (FREIRE, 2009, p. 14).

Propunha-se diante das primeiras experiências de Freire, conforme registro anterior, que, além do carisma cristão (cristianismo), refletiu-se o modelo educacional (dialogação), paralelo à realidade político-social (homem com homem), aliando a ideia educativa como alavanca libertadora do homem e, por isso, do mundo. A perspectiva de Freire, delineada por uma visão humanizadora, libertadora, revolucionária, 
amorosa e política, reflete o contexto cultural, econômico, educativo, ambiental e social. Assim Freire, diz:

Sou esperançado não por obstinação, senão porque sou um ser humano, porque quero e sei que posso, junto com outros e outras, mudar o mundo para melhorá-lo e fazer realidade o sonho utópico de hoje: uma sociedade mais justa, mais bela e mais ética, em suma, mais democrática (2005, p. 64).

A luta de Freire pela valorização da dignidade humana e a justiça, tendo como ferramenta, a educação que faz jus toda sua caminhada munida de resultados satisfatórios, repercutiu para além das fronteiras brasileiras. Segundo Freire (2005), mediante a postura ética e política, foi esperançado por, junto com os outros e outras, mudar o mundo para uma realidade mais justa e democrática. As contribuições freireanas davam respostas aos paradigmas sociais, educacionais, político e econômico da realidade daquele tempo. Por isso, foi classificado como sendo passadista e criminoso, por libertar mentes das trevas.

\title{
IMPACTOS DA CONCEPÇÃO FREIREANA NA CONTEMPORANEIDADE
}

Posto um contexto generalizado da filosofia de Paulo Freire, nas escritas adiante, faremos referência aos impactos provocados pelas contribuições freireanas no cenário brasileiro. Sua marca possibilitou a construção de uma relação intrínseca entre a natureza educacional e a política social.

\begin{abstract}
Seu movimento começou em 1962 no Nordeste, a região mais pobre do Brasil - 15 milhões de analfabetos sobre 25 milhões de habitantes. Neste momento, a "Aliança para o Progresso", que fazia da miséria do Nordeste seu "leitmotiv" no Brasil, interessouse pela experiência realizada na cidade de Angicos, Rio Grande do Norte (interesse que teve seu fim pouco tempo depois da própria experiência). (FREIRE, 1980, p. 17).
\end{abstract}

De modo incontestável, essa mobilização alfabetizadora promovida no interior do Nordeste, foi o ponto de partida que repercutiu nas mais diversas ideologias na sociedade brasileira. Em pouco tempo, 45 dias, cerca de 300 trabalhadores alfabetizados em Angicos, Rio Grande do Norte, uma vez que o tamanho impacto 




Criar Educação, Criciúma, v. 10, nº1, jan/jul 2021.- PPGE - UNESC - ISSN 2317-2452

causado pelo método de Freire despertou os interesses da opinião pública e, mais tarde, decidiu-se aplicar o método em todo território nacional, tendo o apoio do Governo Federal.

"O plano de ação de 1964 previa a instalação de vinte mil círculos de cultura, capazes de formar, no mesmo ano, por volta de dois milhões de alunos" (FREIRE, 1980, p. 18). Para tanto, diante dessa grandiosa mobilização, não apenas por sua ideia, mas por viabilizar a libertação do homem perante a sociedade em que vive, Freire foi acusado como sendo um criminoso por estratégia de subversão.

Os grupos reacionários não podiam compreender que um educador católico se fizesse representante dos oprimidos; com maior razão lhes era impossível admitir que levar a cultura ao povo fosse conduzi-lo a duvidar da validade de seus privilégios. Preferiram acusar Paulo Freire - o ódio pelo comunismo era forte - de ideias que não são as suas, e atacar o movimento de democratização da cultura, no qual percebiam o germe da rebelião baseando-se em que uma pedagogia da liberdade é, por si, forte de rebeldia. (FREIRE, 1980, p. 18).

Nesse sentido, a ótica libertadora de Paulo Freire, frente à realidade existencial dos oprimidos e a sociedade vigente levaram-no ao julgamento que decretou o seu exílio em 1964. Seu método já estava alastrado pelos estados brasileiros e até em outros continentes. Em função disso mesmo, ele foi exilado. Freire continuou suas obras com reflexões que circundam o cenário da injustiça e a desigualdade social.

Sobreposto às marcas na sociedade educativa, Freire contribuiu para 0 avivamento e a ressignificação da pessoa humana, na busca pela justiça e pelo direito, tendo como ferramenta, a Educação Popular. Uma forma de disseminação e de valorização da cultura social, bem como, da reflexão crítica da sociedade política que fundamenta e desenvolve o processo de conscientização. "O movimento de Educação Popular foi uma das numerosas formas de mobilização de massas adotadas no Brasil” (FREIRE, 1980, p. 16). 
Portanto, a sua luta contra o analfabetismo, que o notabilizou nacional e internacionalmente, permanece nos dias atuais, através dos movimentos populares. Isso porque, em pleno século XXI, o índice de analfabetos e de analfabetos funcionais, ainda é alto no meio social brasileiro. E a concepção freireana na contemporaneidade representa o surgimento de muitos caminhos, de novas possibilidades que geram mudança, sendo um pressuposto fundamental que potencializa a práxis educacional, bem como, a valorização da cultura social, da emancipação humana, com o fortalecimento do trabalho dos professores, da prática pedagógica diária, com a utilização de instrumentos que além de mediar a relação professor alunos, desenvolve e potencializa a compreensão da realidade existencial do indivíduo.

\section{Paulo Freire e a EJA: implicações da prática educativa}

Ao discutir as propositivas inerentes à educação de adultos, bem como as suas implicações em tempos de mudança, faz-se imprescindível destacar o principal sujeito do fazer educacional e os desafios que consistem a sua existência no meio em que vive. Freire (2009) sinaliza a grande importância voltada para a humanização pelo simples fato de o homem perceber na sua existência, o sujeito de mudança que ele é, em si. O homem assume uma posição impactante no processo de desenvolvimento de sua espécie, pela fundamental e singular capacidade reflexiva das atitudes e das ações que pode realizar.

A consciência de si revela toda a interioridade que é imanente ao conviver com o outro e com o meio em que vive. Por isso, podemos afirmar que somos seres em processo de construção permanente, diante do espaço em que ocupamos e que fazemos. Diante desta consideração, Freire (2009 p. 50) afirma que "[...] na verdade, o inacabamento do ser ou de sua inconclusão é próprio da experiência vital. Onde há vida, há inacabamento. Mas só entre mulheres e homens o inacabamento se tornou consciente". Diante dessa consciência, nos despertamos como seres de transformação e somos imbuídos no encantamento, na descoberta e na comunhão. 
Por essa razão, entendemos que a participação dos alunos da EJA nas discussões, nos espaços escolares, nas ações, nas tomadas de decisões representa essa descoberta que Paulo Freire evidencia, pois assim, cada um, enquanto sujeito do processo de construção do conhecimento estará exercendo seu papel social e educacional. Ainda sobre os educandos, Freire (1997) alerta sobre a importância de os professores trabalharem a realidade dos alunos da EJA, o seu cotidiano, para aproximá-los da sua prática. Por isso, Freire (2009) considera a emancipação das classes desfavorecidas como sendo uma inevitabilidade histórica. Este ponto de vista implica a concepção do ser humano como "histórico e inacabado" e, consequentemente, sempre pronto a aprender a aprender. No caso particular dos professores, isso se reflete na necessidade de formação rigorosa e permanente. Freire dizia, numa frase famosa, que "[...] o mundo não é, o mundo está sendo" (FREIRE, 2009, p. 45).

Em busca de significados que consolidem o fazer educacional na EJA, em virtude de a consciência do sujeito como ser transformador de realidades, Freire (2009) compreende que ao longo da história, a EJA foi marcada por políticas públicas de descontinuidade e de desvalorização do jovem e do adulto, tornando-os a margem de um sistema educacional que primava pelas condições econômicas de uma minoria. Neste sentido, ele foi o principal defensor desta educação por, justamente acreditar na mudança que implica o processo autêntico de educar. Assim, desenvolveu o método de alfabetização para consolidar o seu pensamento e primar pela valorização do sujeito e de sua cultura, em comunhão e como sendo um ser transformador de sua realidade.

Nessa perspectiva, Brandão (1981, p.10) ressalta que:

Um dos pressupostos do método é a ideia de que ninguém educa ninguém e ninguém se educa sozinho. A educação, que deve ser um ato coletivo, solidário - um ato de amor, dá para pensar sem susto -, não pode ser imposta. Porque educar é uma tarefa de trocas entre pessoas e, se não pode ser nunca feita por um sujeito isolado (até a autoeducação é um diálogo à 
distância), não pode ser também o resultado do despejo de quem supõe que possuí todo o saber, sobre aquele que, do outro lado, foi obrigado a pensar que não possui nenhum. [...] de lado a lado se ensina. De lado a lado se aprende.

Observamos que a educação é um campo de trocas de saberes e, na contemporaneidade, torna-se um palco para a efetivação dos diálogos freireanos, construtivos de uma aprendizagem significativa, que ganha novos espaços, fortalece a essência educadora e a dialogicidade do fazer educacional. Para tanto, o mediador da prática construtora do saber se instala no docente com a devida consciência de que sozinho não constituirá o exercício de ensino e de aprendizagem.

Assim, Freire (2009, p. 51), afirmava que "Os homens se educam entre si mediados pelo mundo". Isso implica na consolidação de um princípio fundamental para Freire: o de que o aluno, alfabetizado ou não, chega à escola levando uma cultura que não é melhor nem pior do que a do professor. Em sala de aula, educando e educador aprendem a aprender juntos, um com o outro, e, para isso, é necessário que as relações sejam afetivas e democráticas, garantindo a todos a possibilidade de expressão, de valorização do individual e do coletivo.

Nesse interim, a valorização da cultura do aluno é a chave para o processo de conscientização preconizado por Paulo Freire, e está no âmago de seu método de alfabetização, que foi formulado inicialmente para o ensino de adultos. A partir do breve ensaio sobre a prática educativa freireana, faz-se necessário estabelecer uma relação existente entre os seus pensamentos e os fazeres construtivos, colocando os desafios do exercício em educar na contemporaneidade, onde as palavras ganham novas formas de representatividade. Neste contexto, os desafios da lógica educacional da EJA intensificam a atuação do docente, passando a exigir um profundo mergulho freireano na realidade contemporânea em que vivemos.

Nessa perspectiva, a realidade que se apresenta na atualidade, evidencia fatores que determinam e restringem a rápida forma de veiculação das informações e das comunicações, aguçando o dia a dia dos educandos que frequentam a EJA. 
Exigem a completa e dinâmica formação para exercer a prática educativa freireana, indo ao encontro das peculiaridades dos sujeitos, que estão presentes nas salas de aula que oferecem a Educação de Jovens e Adultos. São mudanças efetivas que exigem do educador freireano, a busca pela inovação, por mudanças metodológicas, na construção e na revelação dos saberes populares.

É por isso que Peruzzo (2012, p.10) chama a nossa atenção para o fato de que:

\begin{abstract}
$\mathrm{Na}$ chamada sociedade moderna a informação destaca-se visivelmente em relação ao saber. No entanto é fundamental que se verifique a que e a quem servem as informações acumuladas e acorrentadas em partículas disciplinares e em saberes que não estabelecem relações e comunicação. Para que seja saber, a informação precisa de movimento, diálogo, comunicação, tradução. Se aposta, assim, numa ciência que pretende se reinventar para que seja saber, a partir do simbólico, do imaginário e da subjetividade. Os saberes cotidianos e escolares atravessam-se; assim, o diálogo entre os saberes se manifesta de maneira a relacionarem-se entre si.
\end{abstract}

Notamos que se trata de um movimento de circulação das informações e dos saberes, e que, por isso mesmo, necessita de um professor-mediador para atuar na efetivação do processo educacional, para provocar situações inovadoras de aprendizagem. Na concepção freireana, no que diz respeito às implicações do fazer educativo atual, bem como da ideia fundamental do seu método de alfabetização, exige uma performance de educar em tempos contemporâneos, observando a essência de novas culturas e de novas formas dialógicas, que o espaço escolar precisa se adaptar, com a incorporação de metodologias e de instrumentos inovadores, como o uso das tecnologias, para fazer prosperar e oferecer qualidade humana e material ao processo de ensino-aprendizagem das pessoas jovens e adultas.

Desse modo, vale evidenciar as variadas práticas educativas que contribuem para o processo de desenvolvimento de todos os sujeitos da EJA ou das demais modalidades de ensino, destacando a importância de buscar outros modos de conquistar o conhecimento, especialmente, no mundo globalizado em que estamos 
imersos. Ao passo que compreendemos uma evolução referente ao acesso mediático à informação, busca-se metodologias em que correspondem as demandas dos educandos que enfrentam os desafios da atual conjuntura social.

Ao afirmarmos que os sujeitos da EJA são pessoas de história, de cultura e de conhecimento, despertaremos para a nova prática educativa voltada que coloca o educando da EJA como sendo produtor do saber historicamente referenciado, que atua de maneira igualitária, na sociedade da qual, o mesmo, é participante.

Outro ponto que merece destaque é a preocupação com a formação do educador da EJA. Observamos que há um descompasso diante dos processos formativos atuais e as novas exigências freireanas de atuação do educador da EJA. Por isso, Fuhr (2018, p. 97) afirma que "[...] torna-se urgente construir novos modelos de espaço para a construção do conhecimento: emergentes, abertos, contínuos, em fluxo, não lineares, organizados de acordo com os objetivos ou os contextos em que cada um ocupa uma posição singular e evolutiva". E o professor é um agente destas novas concepções formativas, que exigem um repensar, um ponto de partida para concretizar a formação do docente, de modo paralelo a realidade social moderna, vigorando a prática emancipatória educacional da EJA. E realmente buscar por uma formação de educadores com base sólida sobre as teorias pedagógicas (ARROYO, 2017).

Consideramos que a ideia de qualificação para o educador ou educadora da EJA, atualmente, exige uma série de expectativas, que são expressas pelos modelos da sociedade global, uma vez que começamos a identificar, também, os perfis dos alunos que vão à sala de aula, nesta modalidade de ensino. Por isso, a necessidade de um olhar diferenciado para a identidade desses educandos, como pessoas trabalhadoras que necessitam ser valorizadas para terem acesso ao mercado de trabalho qualificado. 
Assim, o perfil do educando da EJA é uma mistura de ricas experiências e de conhecimentos diversos. Por isso, é fundamental partir da voz que pergunta, da experiência que trabalha ou até mesmo, da mente que estuda. Eis a questão norteadora que se aplica a EJA: educar para a vida ou educar para o mercado de trabalho? Na educação para jovens e adultos, muitos retornam em busca dos direitos, não apenas do direito à educação, mas do direito à vida, ao trabalho, à dignidade, à cultura, à voz. O sujeito da EJA tem uma vida fora dos muros escolares com uma dinâmica decorrente de sua própria existência.

Portanto, é no campo da EJA que o conhecimento de vida ganha concretude, longe da exclusão social e entrelaçados com a valorização particular das ricas culturas, que são, muitas vezes ignoradas e silenciadas. Isso pronuncia novas formas de significar a realidade, de possibilitar autonomia aos sujeitos jovens e adultos que por muito tempo tiveram seus direitos negligenciados, mesmo diante das lutas, para que esses trabalhadores possam ser reconhecidos como seres capazes de aprender e de ensinar através de suas experiências de vida.

\section{CONSIDERAÇÕES FINAIS}

O estudo revelou que o momento atual é de grande desafio para todos, alunos, educadores e sociedade. As mudanças no campo da informação exigem que a escola ultrapasse a ideia de novas práticas e métodos de ensino apenas como planejamento pedagógico, mas como ações e posturas críticas que sejam capazes de contribuir, diretamente, com o processo de formação e de escolarização dos alunos da EJA. São sujeitos que há muito tempo esperam ser valorizados e percebidos, como detentores de histórias, carente de outros saberes necessários para melhorar as condições de vida, garantindo o desenvolvimento de competências e de habilidades na atual da sociedade do conhecimento. Assim, reconhecemos que os sujeitos da EJA 
necessitam de maior atenção dos professores, do poder público e de todos os que defendem essa causa.

Estamos convencidos que a formação dos professores representa um dos fatores de grande relevância para as conquistas da educação de jovens e adultos. Neste sentido, entendemos que a escola não pode ficar na inércia, assistindo as mudanças de longe, como se não fosse responsável, também, por esta formação. Chegamos à conclusão que mesmo diante de tantas discussões acerca da educação de jovens e adultos, é preciso continuar lutando e tendo a esperança do verbo esperançar, e acreditar que a escola é o espaço de conquistas, de evolução, de conhecimento, de autonomia e de mudança freireana.

Recomendamos a ampliação desta pesquisa, pois acreditamos que novos olhares possibilitam a melhoria e o repensar das ações pedagógicas, que sejam capazes de fortalecer as relações entre educadores e educandos, sempre, através da leitura crítica da realidade, do repensar de metodologias e de instrumentos de avaliação, considerando o mais importante, o reconhecimento de cada aluno trabalhador e trabalhadora da EJA, do seu valor humano, o seu histórico de vida, o rico conhecimento, as experiências de vida e da certeza de sua contribuição na efetivação de práticas coletivas e democráticas.

Finalizamos esta investigação afirmando que a mesma não se finda neste momento, as inquietações e as necessidades de aprofundamento precisam avançar. Que, e fato, conhecer as contribuições de Paulo Freire para refletir sobre a realidade dos oprimidos diz muito sobre o que presenciamos nas escolas e nas propostas elaboradas pelos governantes para os trabalhadores desta modalidade de ensino. Há, contudo, a certeza de que todos juntos poderemos vencer o desafio do presente, com maior possibilidade de sucesso. 


\section{CRIAR EDUCAÇÃO}

Revista do Programa de Pós-Graduação em Educação - UNESC

Criar Educação, Criciúma, v. 10, nº1, jan/jul 2021.- PPGE - UNESC - ISSN 2317-2452

\section{REFERÊNCIAS}

ARANHA, Maria Lucia de Arruda. História da Educação. 2. ed. São Paulo: Moderna, 1996.

ARROYO, Miguel G. Imagens quebradas - trajetórias e tempos de alunos e mestres. Petrópolis, RJ: Vozes, 2017.

BRANDÃO, Carlos Rodrigues. O que é Método Paulo Freire. 18 ed. São Paulo, Brasiliense. 1981.

FACHIN, Odília. Fundamentos de Metodologia. 3. ed. São Paulo: Saraiva, 2010.

FREIRE, Paulo. Conscientização. Teoria e Prática da Libertação uma Introdução ao

Pensamento de Paulo Freire. São Paulo: Morais, 1980.

São Paulo:

Pedagogia da Autonomia: saberes necessários à prática educativa. 4ed.

Paz e Terra, p.25, 32, 1997.

Pedagogia do Oprimido. 42. ${ }^{\text {a }}$ ed. Rio de Janeiro: Paz e Terra, 2005.

Pedagogia da Esperança: um reencontro com a Pedagogia do Oprimido. Rio de Janeiro: Paz e Terra. 16 ${ }^{\underline{a}}$ ed. 2009. 


\section{CRIAR EDUCAÇÃO}

Revista do Programa de Pós-Graduação em Educação - UNESC

Criar Educação, Criciúma, v. 10, nº1, jan/jul 2021 .- PPGE - UNESC - ISSN 2317-2452

FUHR, R. C. (Re)apreender à docência no contexto da educação digital. Rev. Educ., Brasília, ano 41, n. 157, p. 92-107, out../dez. 2018.

GADOTTI, Moacir. Paulo Freire: uma bibliografia. São Paulo: Cortez,1996.

LAVILLE, Christian. A construção do saber: manual de metodologia da pesquisa em ciências humanas / Christian Laville e Jean Dionne; tradução Heloisa Monteiro e Francisco Settineri. — Porto Alegre: Artmed; Belo Horizonte: Editora UFMQ 1999.

BRASIL. Lei das Diretrizes e Bases da Educação Nacional. Brasília: 2007.

MINAYO, M. C. S. (Org.). Pesquisa Social: Teoria, Método e Criatividade. $21^{a}$ ed. Petrópolis: Vozes, 2002.

PERUZZO, Flávia. Os Saberes Cotidianos dos Idosos: vivências \& conhecimento escolar.

Disponívelem:http://www.ucs.br/etc/conferencias/index.php/anpedsul/9anpedsul/pap er/viewFile/1007/239. Acesso dia 12 de dezembro de 18.

Recebido agosto de 2020

Aprovado março de 2021 
Criar Educação, Criciúma, v. 10, o1, jan/jul 2021.- PPGE - UNESC - ISSN 2317-2452 